\title{
Justice-Forward Teaching: From Detached Learning to Liberation
}

\author{
Jennifer T. Stephens, Laura May Pipe \\ UNC Greensboro, USA
}

\begin{abstract}
In today's global climate of misinformation, conflict, and parallel realities, a justice-forward approach to teaching and learning blends equity and culturally-responsive pedagogies with experiential approaches that lead to direct action and shifting worldviews. Combining common inclusive teaching practices, North American Indigenous learning practices, learners' cultural capital, nonviolent resistance, and processes of reflection and meaningmaking, the TALLS (Toward a Liberated Learning Spirit) model for developing critical consciousness moves learners from detachment through direct action toward liberation. The paper outlines the development of this justice-forward pedagogical model designed for higher education settings but transferable to any cross-disciplinary learning environment.
\end{abstract}

\section{Introduction}

Today's polarized socio-political environments require educators to think intentionally about how pedagogical design can move learners from the development of individual and cultural awareness toward direct action and a liberated understanding of shared fate. Traditionally, the structural inequalities proliferating the socio-political environments that shape learning interactions have been met with justice-seeking approaches. These approaches are often ill-defined and lack engagement with the direct action required for true social change [8]. For educators, the process of moving the learning social consciousness forward to inclusive equity mindedness requires that our pedagogy and teaching practice shift the learning focus from merely identifying systems of oppression to an action-oriented, praxis-based model. Particularly, educators need a justice-forward model that offers clarity on the principles and methods of direct action for developing critical consciousness.

In response to this need for justice-forward praxis, Pipe and Stephens [15] have developed the TALLS (Toward a Liberated Learning Spirit) model for developing critical consciousness, which blends Martin Luther King, Jr.'s [9] Six Steps of Nonviolent Social Change with the sustained wisdom of Indigenous learning practices, cultural wealth frameworks, and traditionally-considered equity approaches. TALLS moves learners from a space of academic detachment and unlearning to direct application and embodied liberation through an organized but non-linear process. Our paper defines the theoretical framework and methodology that led to the creation of the TALLS model and outlines the stages and key features of the model.

\section{Theoretical Framework}

The TALLS model blends established critical concepts of equity with culturally-responsive pedagogy in a focused progression. Embracing the work of Battiste [3], Tanaka [16], Yosso [20], and Wlodkowski and Ginsberg [19], the model aims to chart a process for learning that acknowledges traditionally measured pathways of addressing content while disrupting traditional colonizing teaching practices. Anchored by the intentional use of learning reflection at pivotal moments of transition between stages in the cycle, the model focuses the learning process both internally and externally for the learner.

\subsection{Learning spirit}

In Marie Battiste's [3] work, she describes the power and need of the Learning Spirit:

In Aborigninal thought, the Spirit enters this earth walk with a purpose for being here and specific gifts for fulfilling that purpose... It has a hunger and a thirst for learning, and along that path it leads us to discern what is useful for us to know and what is not. (p. 15)

The Learning Spirit is an essential curiosity, a thirst for knowing while acknowledging that we will never truly know all, going beyond popular understandings of curiosity or lifelong learning. The Learning Spirit is a centering of curiosity focused on the personhood of a learner. In traditional educational processes and practices, this Spirit is often lost. First, we have erased the Learning Spirit through attempts to standardize learning, assessing and achieving benchmarks on a linear learning timeline. Second, the Learning Spirit is diminished by a process of constructing colonized methodologies for validating knowledge [11] that positions Indigenous Knowledge (IK) in a subservient position to Western knowledge processes. Battiste [3] argues for the inclusion of IK for all students as an 
"...extensive and valuable knowledge system that must be made a priority or mission in education" ( $p$. 16). Knowledge must include the honoring and valuing of the Learning Spirit beyond the Indigenous communities of North America and centering IK systems as equal to other knowledge systems.

\subsection{Tender resistance and trust}

Tanaka [16] defines tender resistance as "a decolonizing act of social justice that is simultaneously caring, vulnerable, mindful, and dialogic" and "steeped in the act of a careful, openminded, and generous listening" (p. 24). Like other forms of resistance, tender resistance requires the recognition of colonizing practices normalized over generations and reinforced systemically, manifested collectively, and internalized personally. Unique to tender resistance is the simultaneity of collective hope alongside difficult realities. Engaging in tender resistance necessitates vulnerability, as learners share their deeply held personal and cultural beliefs while also suspending judgment to take on the perspectives of others with different beliefs. Learners hold space for both reality and hopeful possibility through this process of open-minded and open-hearted perspective-taking.

Taking such a potentially precarious approach to resistance necessitates what Tanaka [16] refers to as trusting the learner. Learners come into educational environments with foundations of lived experiences and knowledge as well as evolving curiosities and goals that propel them forward. Creating space for the sharing of these experiences, knowledge, curiosities, and goals means positioning learners as learnerteachers and teachers as teacher-learners, allowing learners to discover and try on ideas at their own pace, and empowering learners to utilize their talents through their own agency. Such a shift in mindset increases student autonomy and deemphasizes prescribed answers and timelines, which can be in conflict with current educational structures and norms. Thus, justice-forward pedagogy requires teacher vulnerability, courage, and the relinquishing of control.

\subsection{Cultural wealth}

Justice-forward pedagogy also moves away from deficit-based approaches to teaching and learning that focus on what knowledge, skills, and experiences learners lack to a process of building on the cultural capital that learners bring into educational spaces. According to Yosso's [20] community cultural wealth model, learners of all backgrounds bring with them multiple forms of cultural capital in the areas of aspirational capital, familial capital, social capital, navigational capital, resistance capital, and linguistic capital. Recognition of this evolving and interdependent cultural wealth means that justiceforward teaching and learning processes leverage learners' resiliency, adaptable communication styles, the balancing of individual agency with a commitment to community and social networks, and personal and collective motivation for transformation.

\subsection{Nonviolent direct action}

The motivation for transformation comes in the form of resistance to the status quo, which can take many forms. A justice-forward approach to resistance recognizes that neither external violence nor internal violence of the spirit brings about lasting social change, as those with privilege are not easily moved to relinquish their privilege. Instead, borrowing from the civil rights activism of King [9], justice-forward pedagogy involves the surfacing of tensions created by injustice through direct action. Justice-forward pedagogy engages learners in experiential learning exercises and community-engaged action that highlight shared fate and the collective impact of injustice anywhere by engaging in information gathering, educating others, affirming personal commitment to justice, negotiating with perpetrators of injustice to seek allyship, illustrating injustice through direct action, and seeking understanding through reconciliation [9].

\subsection{Learning reflection and meaning-making}

Reflection is an essential aspect of the learning process, and the use of Moon's [12, 13, 14] framework for reflection and experiential learning offers a staged-approach to cognitive growth. In her work, Moon argues that reflection sets the conditions needed for learning through a slowing down of activity and application in a way that gives the learner the opportunity to create linkages. The framework starts with noticing as the foundation. Moon asserts that "you cannot learn something if you do not notice it as some level (which could be unconscious)" (p. 6). The first stage operates on the surface of learning with little depth. The second stage, making sense, is a stage of engaging content without making connection to prior knowledge or context. The final three stages are key areas of reflective learning, pushing the learner to connect and pull from previous knowledge with the aim of holistic understanding and engagement. In stage three, making meaning, "there is a sense of meaningfulness but there is not much evidence of going beyond the given" (p. 6). Stage four, working with meaning, moves to creating connections between previous knowledge and context for meaningful depth of understanding. "There is a creation of relationships of new material with other ideas" (p. 6). Lastly, in the transformative learning stage, reflection becomes a central tenant for new idea generation, as students pull together prior learning, experience, and content to 
form new ideas and concepts. "Representation demonstrates strong restructuring of ideas and ability to evaluate the processes of reaching that learning" ( $\mathrm{p}$. 6). Figure 1 shows Moon's [12, 13] reflective learning process coupled with the increasing levels of knowledge and cognitive dimensions found in Revised Bloom's Taxonomy [10].

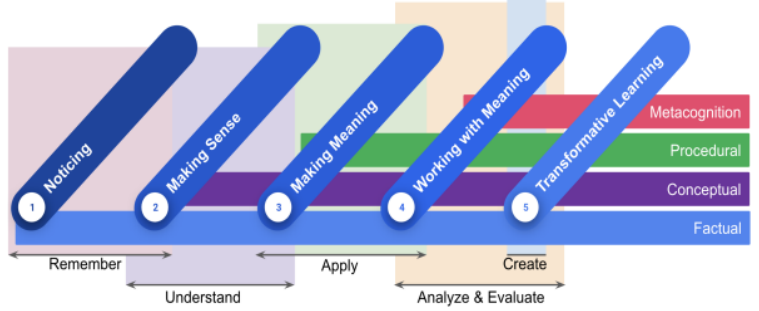

Figure 1. Moon with Revised Bloom's Taxonomy

\section{Methodology}

Pulling together these seemingly disparate approaches to social justice education and inclusive teaching stemmed from a combination of personal experience and cultural observation. In our own roles as educators and faculty developers, we encountered limitations implementing traditional pedagogies and strategies in courses rooted in diversity, equity, and inclusion, as traditional approaches either failed to prepare learners for direct action or failed to move toward direct action at all. At the same time we identified limitations in the many and varied theoretical and pedagogical approaches to social justice education, we observed cultures and communities outside of higher education that seemed to organically embody holistic and inclusive approaches to learning by tapping into individuals' talents and curiosities while also attending to the collective good of the community. To address these limitations in current theories and practices and tap into the wisdom of the communities embodying holistic and inclusive learning practices, we used a grounded theory approach to combine multiple theories and approaches into a new model that offers increased insight into teaching for social justice.

Grounded theory was developed by Glaser and Straus [7] as a structured and rigorous process for developing theories grounded in real world context but was later expanded to use existing theories as data for the development of new theories [17]. According to Apprey [2], grounded theory can be used to combine multiple theories for increased meaningmaking while following the traditional methodology of data collection, coding and categorizing, comparative analysis, memo writing, and theory development [5]. For the creation of the TALLS model for developing critical consciousness, we used a combination of data analysis from a literature review of social justice education and culturally-responsive pedagogies; content analysis of King's [9] principles of nonviolence and steps to nonviolent direct action, Moon's [12, 13, 14] process of learning reflection and meaning-making, and Freire's [6] concept of critical consciousness; and comparison of observation data from the Polynesian Cultural Center and Yosso's [20] community cultural wealth model and North American Indigenous learning practices [16].

\subsection{Literature review}

We [15] reviewed intercultural and social justicerelated literature from the 20th and 21 st centuries and found that theories and pedagogies in social justice education have evolved over time in response to limitations presented by existing social justice approaches as well as emerging issues in society. While each new theory or approach has sought to address a specific limitation or emerging trend, additional gaps have been created. According to a meta-analysis of research on social justice education conducted by Hytten and Bettez [8], social justice education has been difficult to define because of the lack of cohesion between approaches, which they have sorted into five distinct strands: philosophical / conceptual, practical, ethnographic / narrative, theoretically specific, and democratically grounded.

Comparative analysis of the work of Adams [1] and Wlodkowski and Ginsberg [19], have revealed some pedagogical principles and culturallyresponsive practices common to the various approaches to social justice education. These include the establishment of an inclusive learning environment, recognition of multiple positionalities, balance between emotional and cognitive learning, recognition of learner expertise, encouragement of active engagement for enhanced meaning-making, and engenderment of competence and evaluation of personal awareness.

\subsection{Content analysis}

The identification of these common pedagogical principles and practices in social justice education led us to draw parallels to several approaches to meaningmaking that moved beyond awareness to direct action: King's [9] principles of nonviolence and steps to nonviolent direct action, Moon's [12, 13, 14] process of learning reflection and meaning-making, and Freire's [6] concept of critical consciousness. We were able to identify a common process for learning toward direct action and liberation that emerged through content analysis. Analysis of the data revealed that lack of awareness precedes the acquisition of information, which, when processed alongside personal experience and insights from others' experiences, can lead to increased understanding and the ability to make sense of diverse ideas and perspectives. When these ideas are, then, 
applied in experiential or real world applications, learners may engage in increased levels of meaningmaking, with which they can work through direct action in non-classroom contexts. Then, learners' worldviews can be transformed by analyzing and evaluating their experiences with direct action, giving rise to change-making behaviors.

\subsection{Observation data}

The data indicated a learning process that begins with lacking or passive awareness and that moves through direct action to transformation and liberation via the application of specific strategies and principles common to social justice education. The remaining gap to fill in the development of a new justice-forward pedagogical model was to address the conditions for learning essential to inviting participation from traditionally marginalized learners. Utilizing observation data collected from the Polynesian Cultural Center, an applied process of learning that was rooted in cultural traditions, shared storytelling, recognition of inherent gifts / talents / curiosities, and non-linear and individually-timed learning surfaced in the data analysis. Comparing these data to analysis of Yosso's [20] community cultural wealth model and North American Indigenous learning practices [16], we were able to identify a need for an approach grounded in trust, narratives, individual and collective strengths situated in community, real world application, hope, and continuous development.

\section{Findings}

We developed the Toward a Liberating Learning Spirit (TALLS) model (see Figure 2) as a circular (i.e., continuous) process of teaching, learning, and curricular design by, first, identifying the limitations and commonalities across social justice education theories and approaches; then, comparing the data to approaches to meaning-making that extend to direct action; and, finally, observing communities that organically address remaining gaps.

TALLS begins by acknowledging the most traditional version of Western learning - academic detachment. In this process of acknowledging academic detachment, TALLS creates room for the learner to begin reflecting on their own learning experiences. Acknowledgement is expanded by including learner personhoods in an intentional embracing of narratives. The embracing of narratives is essential to disrupting the colonizing impacts of academic detachment that reinforce the privilege of colonizing methodology over other ways of knowing.

The learner, by embracing narratives, is able to move into a space of unlearning that disrupts how the learner believes learning is assessed and valued. The essential practice of experiential-based learning is critical to helping students move from traditionally valued ways of knowing to engaging with their own understandings of the content and the learning process. The experience of unlearning begins a version of what King [9] refers to as "selfpurification," in which the learner must address their own feelings and beliefs related to the learning process. "Self-purification" includes coming to terms with their own experiences (good and bad) in traditional Western learning spaces.

The learner, with reflective self-purification at the forefront, is able to move into a space of application that shifts the learning from conceptual to one of direct action [9]. The use of direct action encourages the learner to conceive of the content in contextualized ways that push the learner to use knowledge across experiences. The direct action shift moves the student closer to a space of liberation, in which the student is able to embody knowledge as part of self and take it outward. The process of taking knowledge outward through embodied critical consciousness [6] is ongoing and lifelong, thus requiring the student to continuously return to academic detachment and begin the cycle again with their newfound understanding.

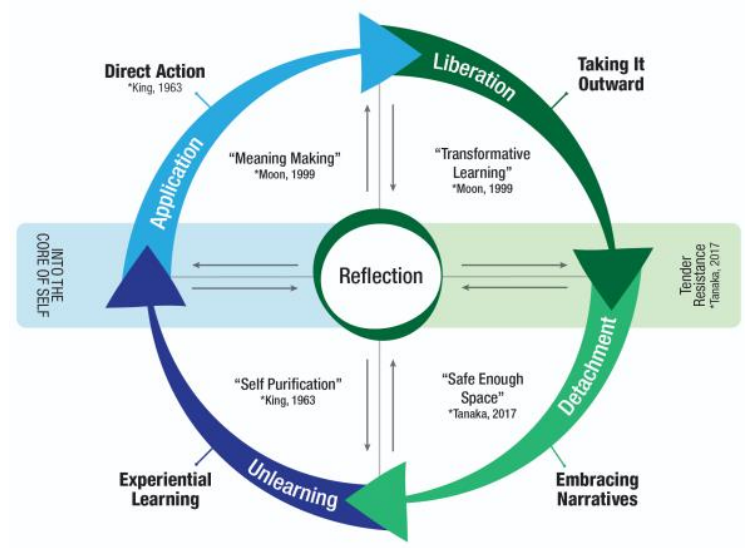

Figure 2. TALLS model

\section{Implications}

A significant challenge to social justice education resides in a tendency for educators to stay within the confines of intellectual pursuits. The challenge is exacerbated by a lack of a cohesive framework that could propel intellectual understandings into directed application and action that lead to the development of critical consciousness. We believe that the TALLS model offers such a framework by providing incremental risk-taking supported by the comfort of intellectual rigor, which is essential if education and educators are to play a role in the development of a more just society, as education is the foundation of intellectual thought and action.

The TALLS framework provides a template for course development that is inclusive of justiceforward outcomes. The model coupled with 
backwards design [18] principles allows an educator to assess the level, process, and desire needed for student learning along a circular progression. For example, the authors used the TALLS model to develop a first- and second-year university-level course examining physical activity and movement in Native communities within the U.S. and Canada. The TALLS model provided the footprint needed to determine how each course learning outcome should be approached, when to introduce activities, the process for building community, and the introduction of applied opportunities. The course focused on the first two sections of TALLS (academic detachment and unlearning) and started the foundations of direct action. Since the course was developed with first- and second-year university students in mind, acclimating students to traditional academic detachment followed by clear opportunities for unlearning was essential for the students' overall understanding of learning (not just the course content). Students indicated that the use of TALLS provided them with a foundation for valuing multiple ways of knowing that included Western conceptions of academic knowledge and local Indigenous knowledge.

In the example, academic detachment incorporated known and documented histories and traditions of Native communities related to physical activity and movement. The course included a process of students examining known literature comparing pre-European contact (prior to 1492 A.D.) and post-European contact examples, current Indigenous literature of traditional practices for health and wellness, and a review of current health challenges faced by Indigenous communities. Students used their own narratives to examine how physical activity is introduced in Western systems as a comparison for understanding potential differences in Indigenous approaches. The course, then, used activities to disrupt or challenge documented histories and traditions in a process of unlearning. The process included examining an archive from the Carlisle Indian Industrial School [4], attendance at the campus Powwow, and engaging with Native stories about sport and games. The activities shifted students' focus from a clinical examination of the topic used in academic detachment to a lived experiential examination requiring students to engage with and uncover potential counter- narratives. The course concluded with the students conducting their own research on a traditional Native sport or game, bringing together their personal and academic examinations. The use of the TALLS model in course design and implementation allowed for students to engage in the learning process as active participants making connections to concepts, the perspectives of others, and their own lived experiences. Thus, the teacher and the students, alike, were both facilitators and creators of knowledge and community.

\section{Conclusion}

Moving from a place of social justice awareness to one of justice-forward action requires reconceptualization of the learning process as one that prepares learners for direct action and provides opportunities for direct action in a supportive environment where learners and educators can process observations, thoughts, and shifting worldviews. In a sociopolitical climate that continues to produce and reproduce inequalities through postcolonial thought, it is the role and work of educators to create and support the foundations of student explorations that serve to disrupt and challenge systems of oppression. The TALLS model offers a non-linear framework for this disruption by allowing educators to examine their own practices, while focusing on decolonizing the learning space. TALLS offers a purposive approach to application and action using educational practice as the springboard for change through a guided approach to traditional social justice practices.

\section{References}

[1] Adams, M. (2016). Pedagogical foundations for social justice education. In M. Adams and L. A. Bell (Eds.), Teaching for diversity and social justice ( ${ }^{\text {rd }}$ ed., pp. 27-53). New York, NY: Routledge.

[2] Apprey, M. (2006). A formal grounded theory on the ethics of transfer in conflict resolution. Mind and Human Interaction, 14, 51-74.

[3] Battiste, M. (2010). Nourishing the Learning Spirit: Living our way to new thinking. Education Canada, 50(1), $14-18$.

[4] Carlisle Indian School Digital Resource. (n.d.). http://carlisleindian.dickinson.edu/ (Access Date: December 15, 2019).

[5] Charmaz, K. (2006). Constructing grounded theory: A practical guide through qualitative analysis. Thousand Oaks, CA: Sage.

[6] Freire, P. (2014). Pedagogy of the oppressed: 30th anniversary edition. https://ebookcentral.proquest.com (Access date: February 5, 2018).

[7] Glaser, B. G., and Strauss, A. L. (1967). The discovery of grounded theory: Strategies for qualitative research. New Brunswick, NJ: Aldine Transaction.

[8] Hytten, K., and Bettez, S. C. (2011). Understanding education for social justice. Educational Foundations, 25(12), 7-24.

[9] King, M. L. (1963). Why we can't wait. Boston, MA: Beacon Press. 
[10] Krathwohl, D. (2002). A revision of Bloom's Taxonomy: An overview. Theory into Practice, 41(4), 212218.

[11] Mignolo, W., and Walsh, C. (2018). The conceptual triad: Modernity / coloniality / decoloniality. On Decoloniality: Concepts analytics praxis. Durham, NC: Duke University Press.

[12] Moon, J. (1999). A handbook of reflective and experiential learning: Theory and practice. London, UK: Routledge Falmer.

[13] Moon, J. (2001). PDP working paper 4: Reflection in higher education learning. LTSN Generic Centre. https://www.brandeis.edu/experientiallearning/currentpdfs/ reflectioninhighered.pdf (Access Date: September 3, 2019).

[14] Moon, J. (2004). A handbook of reflective and experiential learning: Theory and practice. London, UK: Routledge.

[15] Pipe, L. M., and Stephens, J. T. (in press). Toward a Liberated Learning Spirit: A model for developing critical consciousness. Journal of the Scholarship of Teaching and Learning.

[16] Tanaka, M. (2017). Learning and teaching together: Weaving Indigenous ways of knowing into education. Vancouver, BC: University of British Columbia Press.

[17] Wallis, S. E. (2014). Existing and emerging methods for integrating theories within and between disciplines. Journal of Organisational Transformation and Change, 11(1), 3-24.

[18] Wiggins, G. P., and McTighe, J. (2005). Understanding by design (Expanded $2^{\text {nd }} e d$.). Association for Supervision and Curriculum Development.

[19] Wlodkowski, R. J., and Ginsberg, M. B. (1995). A framework for culturally responsive teaching. Educational Leadership, 53(1), 17-21.

[20] Yosso, T. (2006). Whose culture has capital? A critical race theory discussion of community cultural wealth. Race Ethnicity and Education, 8(1), 69-91. 